\title{
Factors affecting mastectomy specimen density in direct-to-implant breast reconstruction
}

\author{
Hyung Suk Yi ${ }^{1}$, Seok Kyung In ${ }^{1}$, \\ Ho Sung Kim ${ }^{1}$, Jin Hyung Park ${ }^{1}$, \\ Hong Il Kim ${ }^{1}$, Chang Wan Jeon ${ }^{2}$, \\ Hyo Young Kim ${ }^{1}$
}

${ }^{1}$ Department of Plastic and Reconstructive Surgery and ${ }^{2}$ Department of Surgery, Kosin University College of Medicine, Busan, Korea
This article was presented as a free paper presentation at PRS Korea 2018 on November 11, 2018, in Seoul, Korea

\begin{abstract}
Background Direct-to-implant breast reconstruction following nipple-sparing mastectomy is becoming increasingly common. The weight of the breast specimen informs implant selection. However, specimens of the same weight may have different volume. Therefore, identifying the factors affecting the density of breast specimens may facilitate the selection of implants with an appropriate volume.

Methods From December 2015 to May 2018, 108 patients underwent direct-to-implant reconstruction following nipple-sparing mastectomy. The weight of the breast specimens was measured using an electronic scale in the operating room. Furthermore, the volume of specimens was measured using the water displacement technique. Multiple regression analysis was performed on factors that can affect breast density, such as menopause, neoadjuvant chemotherapy (CTx), age, body mass index, and diabetes mellitus.

Results The average density of breast specimens in patients older than 50 years $(n=36)$ was $0.96 \pm 0.04 \mathrm{~g} / \mathrm{mL}$, which was significantly lower than the $1.01 \pm 0.08 \mathrm{~g} / \mathrm{mL}$ observed in patients younger than 50 years $(n=72)(P=0.007)$. The mean density of breast specimens in patients who underwent neoadjuvant $\operatorname{CTx}(n=25)$ was $0.96 \pm 0.06 \mathrm{~g} / \mathrm{mL}$, which was significantly lower than the value of $1.00 \pm 0.08 \mathrm{~g} / \mathrm{mL}$ in those who did not $(n=83)$. Conclusions It is advisable to select an implant slightly larger than the mastectomy specimen weight in patients older than 50 years or in those who have undergone neoadjuvant CTx.
\end{abstract}

Keywords Breast density / Mammaplasty / Breast implants

\section{INTRODUCTION}

In the past, radical resection, such as modified radical mastectomy, was preferred for breast cancer. Recently, with the development of implant manufacturing techniques, surgical techniques, and acellular dermal matrix (ADM), direct-to-implant breast reconstruc-

Received: May 28, 2019 Revised: Jul 20, 2019 Accepted: Aug 26, 2019 Correspondence: Hyo Young Kim Department of Plastic and Reconstructive Surgery, Kosin University College of Medicine, 262 Gamcheon-ro, Seo-gu, Busan 49267, Korea

Tel: +82-51-990-6131, Fax: +82-51-990-6312, E-mail: hose3290@naver.com

Copyright @ 2019 The Korean Society for Aesthetic Plastic Surgery.

This is an Open Access article distributed under the terms of the Creative Commons Attribution Non-Commercial License (http://creativecommons.org/licenses/by-nc/4.0/) which permits unrestricted non-commercial use, distribution, and reproduction in any medium, provided the original work is properly cited. www.e-aaps.org tions have been performed with increasing frequency, as they can be completed in a single sitting, prevent donor-site morbidity, and enable a quick return to daily life $[1,2]$.

Several factors should be considered for implant selection, including the patient's and doctor's preferences, ideal breast shape, soft-tissue texture, and match with the contralateral breast. Furthermore, because the weight of the tissue resected due to breast cancer is comparatively easy to measure using a scale, specimen weight is typically used as a factor that informs implant selection [3]. However, since breast tissue properties may differ among patients, the implant size cannot be selected based solely on the weight of the tissue.

The aim of this study was to identify the factors affecting the density of mastectomy specimens, which could help infer the tissue density and subsequently inform implant selection. 


\section{METHODS}

\section{Patients}

We studied 108 women, aged 30-64 years, who had undergone direct-to-implant breast reconstruction with nipple-sparing mastectomy from December 2015 to May 2018. All the patients had been preoperatively diagnosed with breast cancer. Mastectomy and breast reconstruction were performed by an expert breast surgeon and a plastic surgeon, respectively. The patient's age, body mass index (BMI), postmenopausal status, history of neoadjuvant chemotherapy (CTx), tumor size, histology, and diabetes mellitus status were recorded preoperatively. The weight and volume of specimens were measured in the operating room after mastectomy. Histological characteristics were confirmed by the pathological examination results.

\section{Surgical techniques}

The inframammary approach was used for the incision, and reconstruction was performed by a plastic surgeon (JHP) after nipplesparing mastectomy. The procedure began by creating a subpectoral pocket. Subsequently, a portion of the inferomedial muscle was elevated for implant placement. The appropriate size of the implant (selected by the patient during the consultation) was confirmed by surgical judgment, as well as by the weight of the mastectomy specimen. After the implant was placed beneath the muscle-matrix layer, ADM was continuously sutured directly to the inframammary fold at its desired position, completely covering the implant [3].

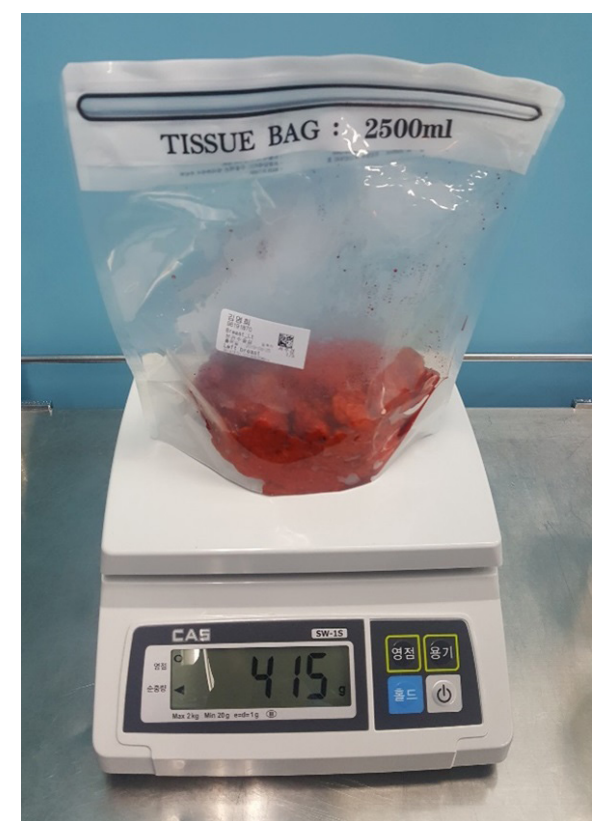

Fig. 1. Measurement of weight by placing the breast specimen on an electric scale.
The weight of the resected tissue was measured in the operating room using an electronic scale (Fig. 1), immediately after the mastectomy tissue was removed from the breast. The weight of the resected tissue was calculated by excluding the weight of the empty container from the total weight. To measure the breast volume, a beaker was placed on a flat surface and filled with $1,000 \mathrm{~mL}$ of normal saline (Fig. 2). The breast tissue was placed in the beaker, and the increase in the water volume was measured and recorded. This method is based on Archimedes' principle of fluid buoyancy [4]. The density was calculated by dividing weight by volume.

\section{Statistical analysis}

Multiple regression analysis was performed to identify the factors affecting breast density. The Student t-test was performed using the selected factors. When the sample size was insufficient, the Mann-Whitney U-test was performed. To compare multiple groups, the Tukey honest significant difference test was used. The statistical analysis was conducted using SPSS version 18.0 (SPSS Inc., Chicago, IL, USA). In all the statistical comparisons, P-values of $<0.05$ were considered to indicate statistical significance.

\section{RESULTS}

A total of 108 patients were studied. Their mean age was 47.5 years (range, 25-64 years), and their mean BMI was $23.25 \pm 2.94 \mathrm{~kg} / \mathrm{m}^{2}$ (range, $18.03-31.29 \mathrm{~kg} / \mathrm{m}^{2}$ ). Neoadjuvant CTx was provided to 25 patients for 6-8 cycles. The mean weight and volume of the mas-

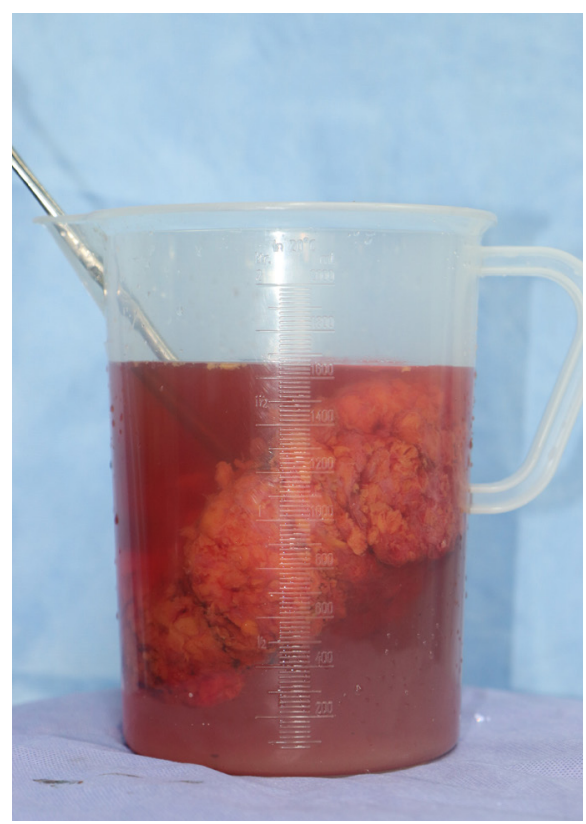

Fig. 2. Measurement of volume by placing the breast specimen in a beaker marked with scale indicators. 
Table 1. Patients' characteristics

\begin{tabular}{lc}
\hline Variable & Value \\
\hline No. of patients & 108 \\
Age lyr) & $47.5 \pm 8.4(25-64)$ \\
BMI (kg/m²) & $23.25 \pm 2.94(18.03-31.29)$ \\
Neoadjuvant chemotherapy & $25(23.1)$ \\
Diabetes mellitus & $2(1.8)$ \\
Postmenopausal status \& density $(\mathrm{g} / \mathrm{mL})$ & \\
Premenopause & $62(57), 0.99 \pm 0.08$ \\
Postmenopause & $45(43), 0.98 \pm 0.06$ \\
Histology & $70(71)$ \\
Invasive carcinoma & $18(19)$ \\
Ductal carcinoma in situ & $4(4)$ \\
Lobular carcinoma in situ & $2(2)$ \\
Microinvasive carcinoma & $4(4)$ \\
No residual malignancy & $12,545.3 \pm 22,456(0-125,000)$ \\
Mean tumor size (mm $\left.{ }^{3}\right)$ & $329.8 \pm 203.4(100-1,078)$ \\
Mean breast specimen volume $(\mathrm{mL})$ & $325.6 \pm 196.2(100-1,025)$ \\
Mean breast specimen weight $(\mathrm{g})$ & $0.99 \pm 0.08(0.83-1.20)$ \\
Mean breast specimen density $(\mathrm{g} / \mathrm{mL})$ &
\end{tabular}

Values are presented as mean \pm SD (range) or number $(\%)$.

$\mathrm{BMI}$, body mass index.

tectomy specimens were $325.6 \pm 196.2 \mathrm{~g}$ (range, 100-1,025 g) and $329.8 \pm 203.4 \mathrm{~mL}$ (range, 100-1,078 $\mathrm{mL}$ ), respectively. The mean breast density was $0.99 \pm 0.08 \mathrm{~g} / \mathrm{mL}$ (range, $0.83-1.20 \mathrm{~g} / \mathrm{mL}$ ) (Table 1).

\section{Multiple regression analysis and Tukey honest significant difference test}

A multiple regression analysis and the Tukey honest significant difference test were performed to detect the factors affecting breast density with respect to age, menopause status, BMI, neoadjuvant CTx, tumor size, diabetes mellitus status, and histology.

Age $(\mathrm{P}=0.015)$ and neoadjuvant $\mathrm{CTx}(\mathrm{P}=0.03)$ were found to be statistically significant factors affecting breast density, while BMI $(\mathrm{P}=0.196)$, tumor size $(\mathrm{P}=0.603)$, menopause $(\mathrm{P}=0.443)$, and histology $(\mathrm{P}=0.4)$ were not. Sufficient records regarding diabetes mellitus were not available for a statistical analysis $(n=2)$.

\section{Student t-test}

Breast density was lower in patients older than 50 years than in those aged 50 years or less. The mean density was $0.96 \pm 0.04 \mathrm{~g} / \mathrm{mL}$ in patients who were older than 50 years $(\mathrm{n}=36)$ and $1.00 \pm 0.08 \mathrm{~g} /$ $\mathrm{mL}$ in those who were aged 50 years or less $(\mathrm{n}=72)$, which was a statistically significant difference $(\mathrm{P}=0.007)$ (Table 2$)$.

The mean density was $0.96 \pm 0.06 \mathrm{~g} / \mathrm{mL}$ in patients who underwent neoadjuvant CTx $(n=25)$ and $1.00 \pm 0.08 \mathrm{~g} / \mathrm{mL}$ in those who did not $(\mathrm{n}=83)$, which was a statistically significant difference $(\mathrm{P}=$ 0.027) (Table 3).
Table 2. The average breast cancer specimen density according to age

\begin{tabular}{cccc}
\hline & $\leq 50$ Years $(\mathrm{n}=72)$ & $>50$ Years $(\mathrm{n}=\mathbf{3 6})$ & P-value $^{\text {a) }}$ \\
\hline Density $(\mathrm{g} / \mathrm{mL})$ & $1.01 \pm 0.08$ & $0.96 \pm 0.04$ & 0.007 \\
\hline
\end{tabular}

Values are presented as mean $\pm \mathrm{SD}$.

al Student t-test.

Table 3. The average breast cancer specimen density according to neoadjuvant CTx

\begin{tabular}{lccc}
\hline & $\begin{array}{c}\text { Non-neoadjuvant } \\
\text { CTx }(\mathrm{n}=83)\end{array}$ & $\begin{array}{c}\text { Neoadjuvant CTx } \\
(\mathrm{n}=25)\end{array}$ & P-value $^{\text {a) }}$ \\
\hline Density $(\mathrm{g} / \mathrm{mL})$ & $1.00 \pm 0.08$ & $0.96 \pm 0.06$ & 0.027 \\
\hline
\end{tabular}

Values are presented as mean $\pm S D$.

CTx, chemotherapy.

a) Student t-test.

Table 4. The average breast cancer specimen density according to neoadjuvant CTx and age

\begin{tabular}{lccc}
\hline & $\begin{array}{c}\leq 50 \text { Years with no } \\
\text { neoadjuvant CTx } \\
(\mathrm{n}=57)\end{array}$ & $\begin{array}{c}>50 \text { Years with } \\
\text { neoadjuvant CTx } \\
(\mathrm{n}=10)\end{array}$ & P-value ${ }^{\text {a) }}$ \\
\hline Density $(\mathrm{g} / \mathrm{mL})$ & $1.01 \pm 0.09$ & $0.95 \pm 0.05$ & 0.012 \\
\hline
\end{tabular}

Values are presented as mean \pm SD.

CTx, chemotherapy.

alMann-Whitney U-test.

The mean density was $0.95 \pm 0.05 \mathrm{~g} / \mathrm{mL}$ in patients who were older than 50 years and underwent neoadjuvant CTx $(n=10)$ and $1.01 \pm 0.09 \mathrm{~g} / \mathrm{mL}$ in those who were 50 years of age and under and did not undergo neoadjuvant CTx $(n=57)$, which was statistically significant according to the Mann-Whitney $\mathrm{U}$-test $(\mathrm{P}=0.012)(\mathrm{Ta}-$ ble 4).

The mean density was $0.99 \pm 0.08 \mathrm{~g} / \mathrm{mL}$ for premenopausal women and $0.98 \pm 0.06 \mathrm{~g} / \mathrm{mL}$ for postmenopausal women, which was not a statistically significant difference $(\mathrm{P}=0.443)$.

\section{DISCUSSION}

The density of breast cancer specimens was significantly lower in patients who underwent neoadjuvant CTx and in those who were older than 50 years.

Neoadjuvant systemic CTx, also known as preoperative CTx, is the standard of care for locally advanced and inoperable tumors and is commonly used to treat patients with early-stage breast cancer [5]. In our study, the mean density of the specimens in the nonneoadjuvant CTx group was $1.00 \pm 0.08 \mathrm{~g} / \mathrm{mL}$, which implied that the weight and volume were almost the same numerically. Thus, for patients who did not undergo neoadjuvant $\mathrm{CTx}$, the specimen weight can be used to determine the volume of the implant [3]. 
However, the mean density of the specimens in the neoadjuvant CTx group was $0.96 \pm 0.06 \mathrm{~g} / \mathrm{mL}$, which was lower than that in the non-neoadjuvant group. In breast cancer, dense tissues are more commonly encountered than normal mammary tissue [6]. Neoadjuvant CTx lowers the ratio of the cancer tissue to the normal tissue, which is thought to lower the density of the mastectomy specimen. The low density implies that specimens of the same weight have a larger volume in cases of neoadjuvant CTx. The percent difference is approximately $4.16 \%$. Therefore, with a mean mastectomy weight of $331.21 \mathrm{~g}$, the volume in the neoadjuvant CTx group would be approximately $13.64 \mathrm{~mL}$ larger than would be calculated by equating the specimen weight measurement $(\mathrm{g})$ with its volume $(\mathrm{mL})$. This should be taken into account when selecting implants for patients who have undergone preoperative CTx.

Breast density was significantly lower in patients who were older than 50 years. Glandular tissue begins to atrophy with age. The breast lobules involute, with reductions in the number and size of acini per lobule. Over time, the glandular elements of the breast are progressively replaced by fat and connective tissue $[7,8]$. Our study showed that the density in patients older than 50 years was $0.96 \mathrm{~g} /$ $\mathrm{mL}$, which was $4.16 \%$ lower than that of tissues of the same weight in patients younger than 50 years. Therefore, for elderly patients, it is advisable to prepare an implant slightly larger than the size that would be selected based on specimen weight, as is also the case for neoadjuvant CTx patients. Unlike Western women, in whom breast density does not differ with age on mammography, breast density rapidly decreases in Koreans when they are older than 50 years [9]. Our results also showed that breast density decreased after the age of 50 years.

Patients who were over 50 years old and had undergone neoadjuvant CTx had a mean breast density of $0.95 \pm 0.05 \mathrm{~g} / \mathrm{mL}$, which was $5.26 \%$ lower than that of tissues of the same weight in the overall patient sample. This would imply that if the weight of the specimen is $331.21 \mathrm{~g}$, it needs to be replaced with a volume of 348.63 mL. BellaGel (Hans Biomed, Daejeon, Korea), which we mainly use for reconstruction, produces implants with $25-\mathrm{mL}$ differences. Therefore, patients who are older than 50 years and have undergone neoadjuvant CTx should receive an implant one size bigger than the implant size that would be selected directly based on the specimen weight.

A study reported that there was a close association between breast weight and volume, regardless of menopausal status. In that study, pre- and post-menopausal densities were 1.07 and $1.06 \mathrm{~g} / \mathrm{mL}$, respectively [10]. It was concluded that the replaced volume could be the same as that decided based on the specimen weight. However, in our study, we found that patients who were older than 50 years and underwent neoadjuvant $\mathrm{CTx}$ could be under-corrected by replacement with a volume equal to that determined based on the actual weight. We expected that since menopause most often occurs around the age of 50 years, it would affect breast density, but a

statistically significant relationship between menopausal status and breast density was not found in our study. This was probably because of patients aged $<50$ years who had early menopause, or those who had not undergone menopause even after the age of 50 years. More, larger studies are needed to determine whether menopause affects density.

Several methods of measuring breast volume before surgery have been introduced [11-13], such as magnetic resonance imaging, thermoplastic molding, anatomical measurements, preoperative application of Archimedes' principle, mammography, use of the Grossman-Rounder device, and three-dimensional scanning. However, they have the disadvantages of preoperative equipment availability and excessive time consumption. In this study, the specimen weight could be used to easily determine the volume.

Our study has limitations. Breast reconstruction requires restoration of both volume and symmetry with the contralateral breast $[14,15]$. Therefore, in patients with severe asymmetry, it will be difficult to use the results of this study for implant selection, which is performed using a sizer in the sitting position intraoperatively. In addition, as the breast on the side of the implant may feel heavier than anticipated, the weight should be discussed with the patient before surgery. Moreover, although tissue damage by an electrocautery tool, such as a Bovie knife during surgery, can also affect specimen density, this was not considered in our study.

In conclusion, patients older than 50 years or those who have undergone neoadjuvant $\mathrm{CTx}$ require restoration with a volume larger (by approximately $5.26 \%$ ) than that determined directly based on the specimen weight, and this should be considered when selecting implants.

\section{NOTES}

\section{Conflict of interest}

No potential conflict of interest relevant to this article was reported.

\section{Ethical approval}

The study was approved by the Institutional Review Board of Kosin University Gospel Hospital (IRB No. KUGH 2019-05-029) and performed in accordance with the principles of the Declaration of Helsinki. The informed consent was waived.

\section{ORCID}

Hyung Suk Yi Seok Kyung In Ho Sung Kim Jin Hyung Park Hong Il Kim Chang Wan Jeon Hyo Young Kim https://orcid.org/0000-0002-9584-8201 https://orcid.org/0000-0003-4346-7949 https://orcid.org/0000-0002-6030-3199 https://orcid.org/0000-0001-9415-2467 https://orcid.org/0000-0002-5505-9945 https://orcid.org/0000-0003-4312-521X https://orcid.org/0000-0002-1834-5766 


\section{REFERENCES}

1. Boyd KU, Temple CL, Ross DC. Factors affecting surgical wait times for breast reconstruction. Can J Plast Surg 2010;18:107-11.

2. Gdalevitch P, Ho A, Genoway K, et al. Direct-to-implant single-stage immediate breast reconstruction with acellular dermal matrix: predictors of failure. Plast Reconstr Surg 2014;133:738e-747e.

3. Salzberg CA. Focus on technique: one-stage implant-based breast reconstruction. Plast Reconstr Surg 2012;130(5 Suppl 2):95S-103S.

4. Schultz RC, Dolezal RF, Nolan J. Further applications of Archimedes' principle in the correction of asymmetrical breasts. Ann Plast Surg 1986;16:98-101.

5. Liu SV, Melstrom L, Yao K, et al. Neoadjuvant therapy for breast cancer. J Surg Oncol 2010;101:283-91.

6. Shepherd JA, Kerlikowske K, Ma L, et al. Volume of mammographic density and risk of breast cancer. Cancer Epidemiol Biomarkers Prev 2011;20:1473-82.

7. Cowan DF. Involution of the breast in women aged 50 to 104 years: a histopathological study of 102 cases. Surg Pathol 1989;2:323-33.

8. Hutson SW, Cowen PN, Bird CC. Morphometric studies of age related changes in normal human breast and their significance for evolution of mammary cancer. J Clin Pathol 1985;38:281-7.

9. Kim SH, Kim MH, Oh KK. Analysis and comparison of breast density according to age on mammogram between Korean and Western women. J Korean Radiol Soc 2000;42:1009-14.

10. Parmar C, West M, Pathak S, et al. Weight versus volume in breast surgery: an observational study. JRSM Short Rep 2011;2:87.

11. Bulstrode N, Bellamy E, Shrotria S. Breast volume assessment: comparing five different techniques. Breast 2001;10:117-23.

12. Kayar R, Civelek S, Cobanoglu M, et al. Five methods of breast volume measurement: a comparative study of measurements of specimen volume in 30 mastectomy cases. Breast Cancer (Auckl) 2011;5:43-52.

13. Kovacs L, Eder M, Hollweck R, et al. Comparison between breast volume measurement using 3D surface imaging and classical techniques. Breast 2007;16:137-45.

14. Salzberg CA, Ashikari AY, Koch RM, et al. An 8-year experience of direct-to-implant immediate breast reconstruction using human acellular dermal matrix (AlloDerm). Plast Reconstr Surg 2011;127:514-24.

15. Colwell AS, Tessler O, Lin AM, et al. Breast reconstruction following nipple-sparing mastectomy: predictors of complications, reconstruction outcomes, and 5-year trends. Plast Reconstr Surg 2014;133:496506. 